\title{
Boron-10 ABUNCL Active Testing
}

Richard T. Kouzes

James H. Ely

Azaree T. Lintereur

Edward R. Siciliano

July 2013

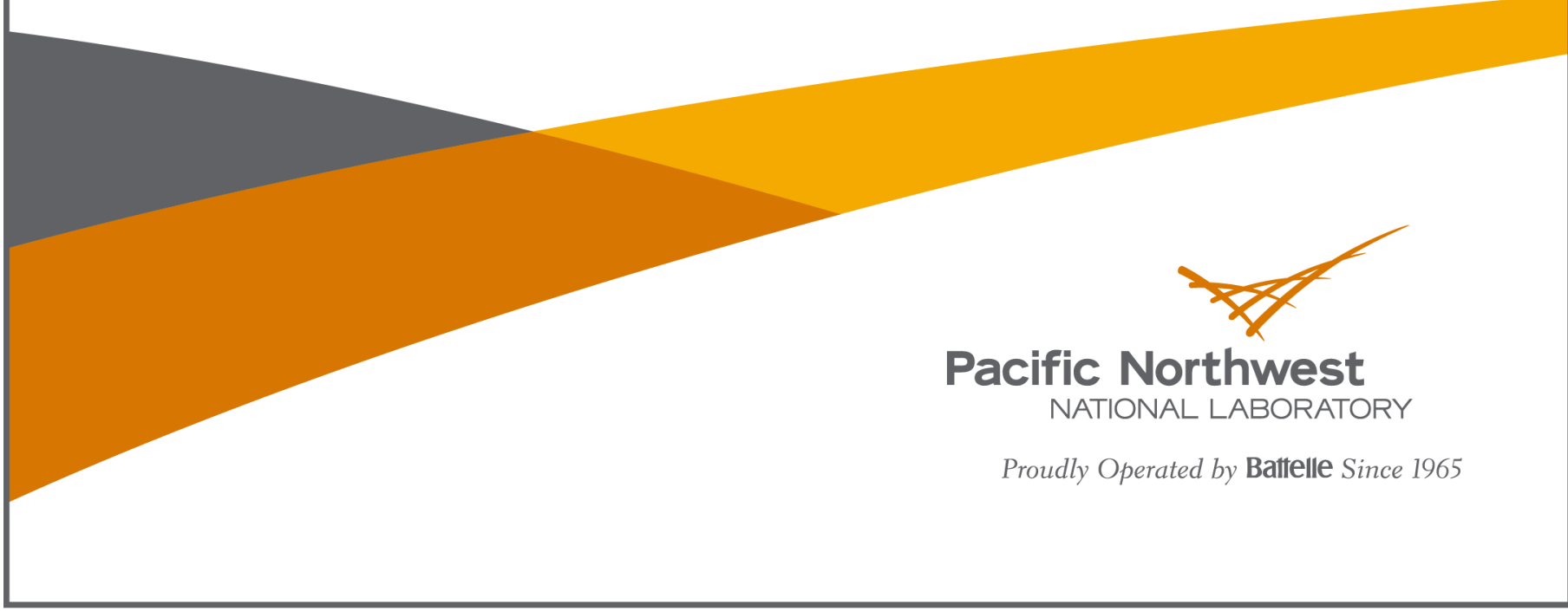




\title{
DISCLAIMER
}

This report was prepared as an account of work sponsored by an agency of the United States Government. Neither the United States Government nor any agency thereof, nor Battelle Memorial Institute, nor any of their employees, makes any warranty, express or implied, or assumes any legal liability or responsibility for the accuracy, completeness, or usefulness of any information, apparatus, product, or process disclosed, or represents that its use would not infringe privately owned rights. Reference herein to any specific commercial product, process, or service by trade name, trademark, manufacturer, or otherwise does not necessarily constitute or imply its endorsement, recommendation, or favoring by the United States Government or any agency thereof, or Battelle Memorial Institute. The views and opinions of authors expressed herein do not necessarily state or reflect those of the United States Government or any agency thereof.

\author{
PACIFIC NORTHWEST NATIONAL LABORATORY \\ operated by \\ BATTELLE \\ for the \\ UNITED STATES DEPARTMENT OF ENERGY \\ under Contract DE-AC05-76RL01830
}

Printed in the United States of America

\author{
Available to DOE and DOE contractors from the \\ Office of Scientific and Technical Information, \\ P.O. Box 62, Oak Ridge, TN 37831-0062; \\ ph: (865) 576-8401 \\ fax: (865) 576-5728 \\ email: reports@adonis.osti.gov
}

Available to the public from the National Technical Information Service, U.S. Department of Commerce, 5285 Port Royal Rd., Springfield, VA 22161

ph: (800) 553-6847

fax: (703) 605-6900

email: orders@ntis.fedworld.gov

online ordering: http://www.ntis.gov/ordering.htm 


\title{
Boron-10 ABUNCL Active Testing
}

\author{
Richard T. Kouzes
}

James H. Ely

Azaree T. Lintereur

Edward R. Siciliano

July 2013

Pacific Northwest National Laboratory

Richland, Washington 99352 


\section{Executive Summary}

The Department of Energy Office of Nuclear Safeguards and Security (NA-241) is supporting the project Coincidence Counting With Boron-Based Alternative Neutron Detection Technology at Pacific Northwest National Laboratory (PNNL) for the development of a ${ }^{3} \mathrm{He}$ proportional counter alternative neutron coincidence counter. The goal of this project is to design, build and demonstrate a system based upon ${ }^{10} \mathrm{~B}$-lined proportional tubes in a configuration typical for ${ }^{3} \mathrm{He}-$ based coincidence counter applications.

This report provides results from testing the active mode version of the General Electric ReuterStokes Alternative Boron-Based Uranium Neutron Coincidence Collar (ABUNCL) at Los Alamos National Laboratory using sources and fresh fuel pins. The measurements indicate that a $1 \%$ doubles measurement can be made in about 30 minutes with this instrument. This time period may be acceptable for safeguards measurements by inspectors, but that operational question needs to be answered by the IAEA. 


\section{Acronyms and Abbreviations}

\begin{tabular}{ll} 
ABUNCL & Alternative Boron-Based Uranium Neutron Coincidence Collar \\
AmLi & Americium-lithium neutron source \\
BWR & Boiling water reactor \\
cps & Counts per second \\
D & Doubles \\
DOE & U.S. Department of Energy \\
DU & Depleted uranium \\
$\varepsilon$ & Detection efficiency \\
FOM & Figure of Merit \\
GE & General Electric \\
GERS & General Electric Reuter-Stokes \\
HDPE & High Density Polyethylene \\
IAEA & International Atomic Energy Agency \\
LANL & Los Alamos National Laboratory \\
LEC & Low-Energy Cutoff \\
LEU & Low-enriched uranium \\
MCA & Multi-Channel Analyzer \\
MOX & Mixed Oxide fuel \\
NIM & Nuclear Instrumentation Module \\
NIST & National Institute of Science and Technology \\
PHL & Pulse-Height Light \\
PNNL & Pacific Northwest National Laboratory \\
Pu & Plutonium \\
S & Singles \\
$\tau$ & Die-away time \\
TTL & Transistor-transistor logic \\
U & Uranium \\
UNCL & Uranium Neutron Coincidence Collar \\
& \\
\hline &
\end{tabular}




\section{Contents}

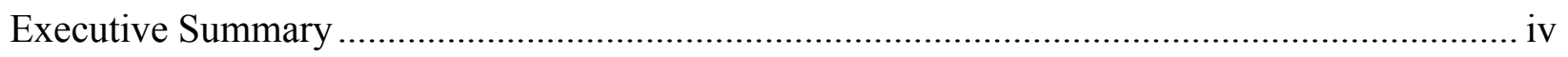

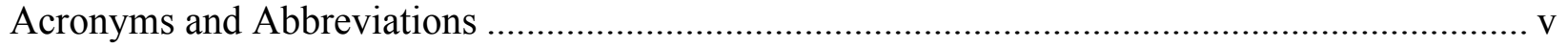

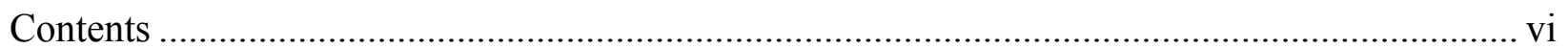

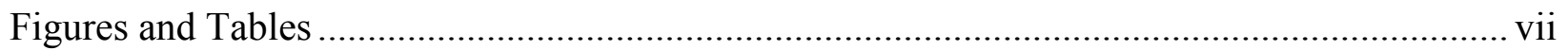

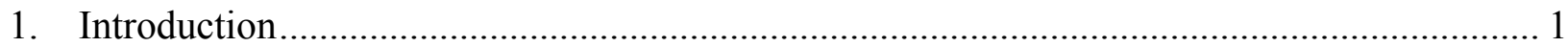

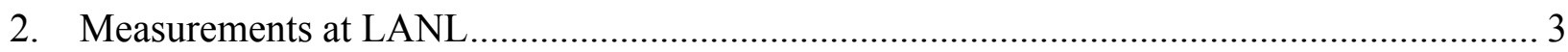

3. Efficiency and Dead Time Measurements …................................................................. 5

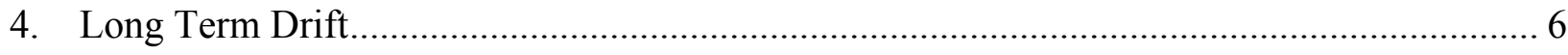

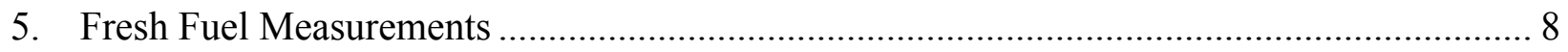

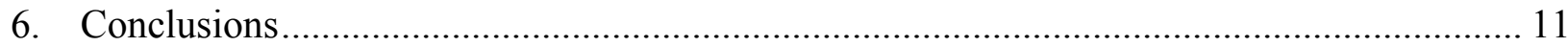

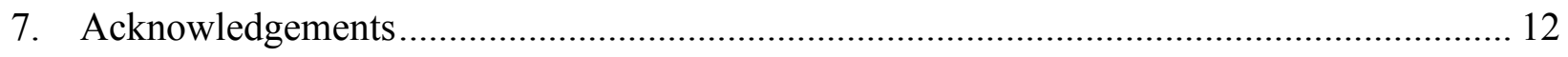

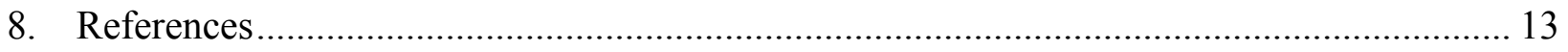




\section{Figures and Tables}

\section{Figures}

Figure 1.1. GE Reuter Stokes ABUNCL at LANL. ............................................................ 2

Figure 4.1. Temperature variation at LANL from May 14 to June 11, 2013 measured every 5

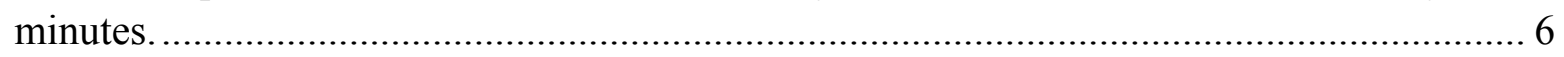

Figure 4.2. Singles counts at LANL from May 14 to June 11, 2013 measured every 10 minutes. 7

Figure 5.1. ABUNCL at LANL with fuel pins loaded (DU in the center, LEU on outside)......... 8

Figure 5.2. Fuel configurations used during measurements, where blue represents LEU pins, black are guide tubes, white are DU pins. .............................................................. 9

Figure 5.3. Doubles rates from fuel measurements. ......................................................... 10

\section{Tables}

Table 1.1. Characteristics of UNCL and ABUNCL configurations [Kouzes 2012]................... 2

Table 2.1. Sources used at LANL................................................................................ 3

Table 2.2. Measurements at LANL on May 14, 2013 ...................................................... 3

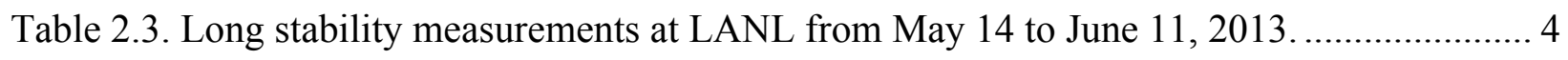

Table 2.4. Measurements at LANL on June 11-12, 2013 .................................................. 4 


\section{Introduction}

The search for technological alternatives to ${ }^{3} \mathrm{He}$ is a major research area in nuclear security and safeguards due to the shortage of this gas in recent years [Kouzes 2010; Menlove 2011]. One of the important safeguards applications of ${ }^{3} \mathrm{He}$ has been for coincidence counting instruments. The Department of Energy Office of Nuclear Safeguards and Security (NA-241) is supporting the project Coincidence Counting With Boron-Based Alternative Neutron Detection Technology at Pacific Northwest National Laboratory (PNNL) for the development of a ${ }^{3} \mathrm{He}$ proportional counter alternative neutron coincidence counter. The goal of this project is to design, build and demonstrate a system based upon ${ }^{10} \mathrm{~B}$-lined proportional tubes in a configuration typical for ${ }^{3} \mathrm{He}-$ based coincidence counter applications.

General Electric (GE) Reuter-Stokes (Twinsburg, $\mathrm{OH}$ ) developed a passive coincidence collar prototype based on arrays of ${ }^{10} \mathrm{~B}$-lined tubes using Ar fill gas. That prototype was loaned to PNNL for testing against the safeguards requirements for an Alternative Boron-based Uranium Neutron Coincidence Collar (ABUNCL) [McKinny 2012; Kouzes 2012]. It was also reconfigured for use in an active mode, and initial testing of the active configuration was also performed at PNNL [Kouzes 2013]. Subsequently, the ABUNCL was taken to Los Alamos National Laboratory (LANL) for testing with fresh low-enriched uranium (LEU) nuclear fuel.

The ABUNCL, as delivered by GE Reuter-Stokes, was configured in a passive boiling water reactor (BWR) coincidence collar configuration. This was modified to an active BWR configuration by replacing one side of the detector with a removable high-density polyethylene (HDPE) door. The shape and size of this HDPE block was not optimized, potentially increasing the die-away time of the system. Listed in Table 1.1 is comparative data characterizing the two ${ }^{3} \mathrm{He}$-based active BWR configurations, and the ABUNCL.

The ${ }^{3} \mathrm{He}$-based active BWR UNCL-II has the largest figure-of-merit (FOM) listed in the table, defined as FOM $=\varepsilon^{2} / \tau$. The GE Reuter-Stokes active ABUNCL configuration initial experimental and modeling results were reported in [Kouzes 2013]. While the GE Reuter-Stokes design was targeting the UNCL-I FOM of 3.1, its performance falls below that value with a FOM of 1.7.

Based on the previous measurements at PNNL, the pre-delay time for the ABUNCL was chosen as $4 \mu \mathrm{s}$ and the gate width was chosen as $100 \mu \mathrm{s}$. The preamplifiers (PDT10A/20A) all had a 150 $\mathrm{keV}$ threshold and the boron-lined tubes had an operating voltage of $750 \mathrm{~V}$. Engineering students from Washington State University developed a mechanical lift for the ABUNCL that allows the system to be rolled around and lifted to the required height for measurements, as shown in Figure 1.1 in the lab at LANL.

The ABUNCL system was set up and initially tested at LANL on May 14, 2013, and tested with fresh fuel assemblies at LANL on June 11-12, 2013. Measurements were also made of the system stability between these dates. All data were acquired with a JSR-14 shift register (Canberra Industries, Meriden, CT) and a laptop running the INCC code [Krick 2009]. This paper reports on the results of the active testing activities with fresh nuclear fuel. 
Table 1.1. Characteristics of UNCL and ABUNCL configurations [Kouzes 2012].

\begin{tabular}{|c|c|c|c|c|c|c|c|c|}
\hline \multirow{3}{*}{ Detector } & \multirow{3}{*}{$\begin{array}{c}\text { Total \# Tubes, } \\
\text { Configuration, \& } \\
\text { Fuel Cavity } \\
\text { H x L x W (cm) }\end{array}$} & \multirow{3}{*}{$\begin{array}{l}\text { Total } \\
\text { No. } \\
\text { Moles }\end{array}$} & \multicolumn{6}{|c|}{ Efficiency $(\varepsilon)$, Die-Away Time $(\tau) \&$ FOM $=\varepsilon^{2} / \tau$} \\
\hline & & & \multicolumn{3}{|c|}{ Measurement Results } & \multicolumn{3}{|c|}{ Model Results } \\
\hline & & & $\varepsilon$ & $\begin{array}{c}\tau \\
(\mu \mathrm{s}) \\
\end{array}$ & $\begin{array}{c}\text { FOM } \\
(\%)^{2} / \mu \mathrm{s} \\
\end{array}$ & $\varepsilon$ & $\begin{array}{c}\tau \\
(\mu \mathrm{s})\end{array}$ & $\begin{array}{c}\text { FOM } \\
(\%)^{2} / \mu \mathrm{s}\end{array}$ \\
\hline $\begin{array}{l}\text { UNCL-I } \\
\text { Active } \\
\text { BWR }\end{array}$ & $\begin{array}{l}18{ }^{3} \mathrm{He} \text { tubes } \\
3 \text { Rectangular banks, } \\
41.4 \times 16.5 \times 23.4\end{array}$ & 0.44 & $13.5 \% *$ & & & $12.5 \%$ & 50 & 3.1 \\
\hline $\begin{array}{l}\text { UNCL-II } \\
\text { Active } \\
\text { BWR }\end{array}$ & $\begin{array}{l}16{ }^{3} \mathrm{He} \text { tubes } \\
3 \text { Rectangular banks } \\
41.3 \times 16.5 \times 16.5\end{array}$ & 0.39 & $\begin{array}{c}15.3 \% * * \\
15.4 \% * \\
13.5 \% \\
( \pm 10 \%)^{* * *} \\
\end{array}$ & $58 * *$ & 4.0 & $14.9 \%$ & 53 & 4.2 \\
\hline $\begin{array}{l}\text { GE RS } \\
\text { ABUNCL } \\
\text { Active } \\
\text { BWR**** }\end{array}$ & $\begin{array}{l}56{ }^{10} \mathrm{~B} \text {-lined tubes } \\
3 \text { Rectangular banks } \\
78.1 \times 16.5 \times 23.4\end{array}$ & NA & $9.4 \%$ & 83 & 1.1 & $11.5 \%$ & 77 & 1.7 \\
\hline & & & & & & & & \\
\hline
\end{tabular}

* From [Menlove et al. 1990] using ${ }^{252} \mathrm{Cf}$ centered in sample chamber

** $\quad$ From [Croft et al. 2011] using ${ }^{252} \mathrm{Cf}$ centered in sample chamber

*** From [Canberra 2011] for JCC-72 using active measurement

**** From [Kouzes 2013] using a $150 \mathrm{keV}$ low energy threshold

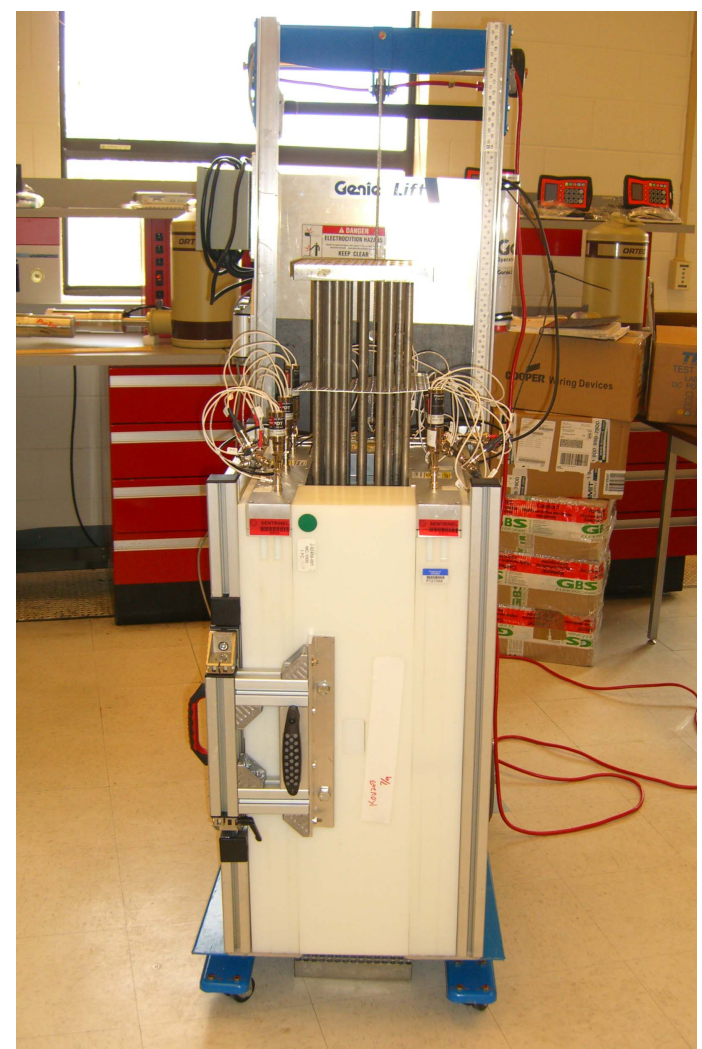

Figure 1.1. GE Reuter Stokes ABUNCL at LANL. 


\section{Measurements at LANL}

All measurements discussed in this report were made at LANL in area TA-35, Building 2. After the system was assembled, the efficiency and the dead time were measured on May 14, 2013 in room C-154. Some extended runs were initiated to look at long-term stability, covering the period from May 14 to June 11, 2013.

Measurements on depleted uranium (DU) and LEU fuel rods (3.19\% enriched) were made on June 11-12, 2013 in Room C-157.

The neutron sources used at LANL are summarized in Table 2.1, including two AmLi sources and two ${ }^{252} \mathrm{Cf}$ sources. LANL provided the neutron emission rate (determined from comparison to a standard source) and the derived source activity for the date of measurement, and stated that uncertainties for these source values were typically $\sim 1.5 \%$. The sources were enclosed in small metal pigs.

Table 2.1. Sources used at LANL.

\begin{tabular}{|c|c|c|c|}
\hline Source & Number & Activity $(\boldsymbol{\mu C} \mathbf{i})$ & Neutrons $\left(\mathbf{s}^{-\mathbf{1}}\right)$ \\
\hline${ }^{252} \mathrm{Cf}$ & $\mathrm{A} 7-866$ & 31.0 & $1.09 \times 10^{5}$ \\
\hline${ }^{252} \mathrm{Cf}$ & $\mathrm{A} 7-867$ & 55.6 & $2.11 \times 10^{5}$ \\
\hline $\mathrm{AmLi}$ & $\mathrm{N}-160$ & $1.17 \times 10^{6}$ & $4.5 \times 10^{4}$ \\
\hline $\mathrm{AmLi}$ & $\mathrm{N}-161$ & $1.17 \times 10^{6}$ & $4.5 \times 10^{4}$ \\
\hline
\end{tabular}

Listed in Table 2.2 is the information on the initial measurements performed at LANL on May 14,2013 . The first measurement acquired was a background. The recorded singles rate was 9.7(1) cps (Run 1). The values in parentheses are the reported uncertainties in the last digit shown. All uncertainties are statistical as reported by the INCC code.

The data taken in Runs 4-7 with the ${ }^{252} \mathrm{Cf}$ sources was for the purpose of acquiring a dead time measurement. Run 5 was aborted when another source entered the room and was not used in the analysis. To account for any scattering or attenuation by the second source, each of the single source measurements were made with a "dummy" source of the same shield dimensions and composition as a real source also in place.

Table 2.2. Measurements at LANL on May 14, 2013.

\begin{tabular}{|c|l|c|c|c|}
\hline Run & \multicolumn{1}{|c|}{ Configuration } & Time (s) & $\begin{array}{c}\text { Singles } \\
\left(\mathbf{s}^{-1}\right)\end{array}$ & $\begin{array}{c}\text { Doubles } \\
\left(\mathbf{s}^{-1}\right)\end{array}$ \\
\hline 1 & Background & 300 & $9.7(1)$ & 0 \\
\hline 2 & Background contaminated by source & - & & \\
\hline 3 & $55.6 \mu \mathrm{Ci}^{252} \mathrm{Cf}$ in detector center & 600 & $20304(60)$ & $1805(140)$ \\
\hline 4 & $55.6 \mu \mathrm{Ci}^{252} \mathrm{Cf}$ with dummy source on inside door & 3600 & $11607(2)$ & $547(3)$ \\
\hline 5 & $55.6 \mu \mathrm{Ci}^{252} \mathrm{Cf}$ with dummy source on inside door & 1080 & $11602(4)$ & $546(6)$ \\
\hline 6 & $31.0 \& 55.6 \mu \mathrm{Ci}^{252} \mathrm{Cf}$ source on inside door & 3600 & $17478(2)$ & $818(4)$ \\
\hline 7 & $31.0 \mu \mathrm{Ci}{ }^{252} \mathrm{Cf}$ with dummy source on inside door & 3600 & $5964(1)$ & $278(2)$ \\
\hline 8 & Two AmLi sources inside source location & 300 & $4947(4)$ & $1(4)$ \\
\hline
\end{tabular}


Listed in Table 2.3 is the information on long-term drift measurements made between May 14, 2013 and June 11, 2013 in Room C-154. Gaps of some hours to a day exist between

measurements. The values in parentheses are the reported uncertainties in the last digit shown.

Table 2.3. Long stability measurements at LANL from May 14 to June 11, 2013.

\begin{tabular}{|c|c|c|c|c|c|}
\hline Run & Configuration & Dates & $\begin{array}{c}\text { Time } \\
(\mathbf{s})\end{array}$ & $\begin{array}{c}\text { Singles } \\
\left(\mathbf{s}^{-1}\right)\end{array}$ & $\begin{array}{c}\text { Doubles } \\
\left(\mathbf{s}^{-\mathbf{1}}\right)\end{array}$ \\
\hline 9 & Two AmLi sources inside source location & May 14 - 20 & 487,200 & $4893.6(2)$ & $1.2(1)$ \\
\hline 10 & Two AmLi sources inside source location & May 20 - 22 & 181,800 & $4899.5(2)$ & $1.5(2)$ \\
\hline 11 & Two AmLi sources inside source location & May 22 - 28 & 501,600 & $4880.6(2)$ & $1.2(1)$ \\
\hline 12 & Two AmLi sources inside source location & May 28 - June 4 & 597,000 & $4879.4(2)$ & $1.5(1)$ \\
\hline 13 & Two AmLi sources inside source location & June 5 - 11 & 483,000 & $4863.7(2)$ & $1.4(1)$ \\
\hline
\end{tabular}

Listed in Table 2.4 is the information on the measurements performed at LANL on June 11-12, 2013, in Room C-157. The values in parentheses are the reported uncertainties in the last digit shown. The "Doubles \% Error" is the uncertainty listed in the "Doubles" column divided by the rate listed. It is desirable that measurements of a complete fuel assembly have a doubles precision of $\sim 1 \%$, which dictates the amount of time required for measurements. The analysis of the data from these measurements is discussed below.

Table 2.4. Measurements at LANL on June 11-12, 2013.

\begin{tabular}{|c|l|c|c|c|c|}
\hline Run & \multicolumn{1}{|c|}{ Configuration } & $\begin{array}{c}\text { Time } \\
(\mathbf{s})\end{array}$ & $\begin{array}{c}\text { Singles } \\
\left(\mathbf{s}^{-1}\right)\end{array}$ & $\begin{array}{c}\text { Doubles } \\
\left(\mathbf{s}^{-1}\right)\end{array}$ & $\begin{array}{c}\text { Doubles } \\
\mathbf{\%} \text { Error }\end{array}$ \\
\hline 1 & Background & 1000 & $25.9(1)$ & $0.01(1)$ & $100.0 \%$ \\
\hline 2 & 72 DU pins with AmLi source & 1480 & $2758(1)$ & $14(1)$ & $0.8 \%$ \\
\hline 3 & 56 DU plus 16 center LEU pins with AmLi source & 3950 & $2916(1)$ & $32.2(7)$ & $1.9 \%$ \\
\hline 4 & 56 DU plus 16 outside LEU pins with AmLi source & 2950 & $2951(1)$ & $37.4(7)$ & $7.1 \%$ \\
\hline 5 & 56 DU plus 16 rear LEU pins with AmLi source & 2875 & $2875(1)$ & $33.2(7)$ & $2.2 \%$ \\
\hline 6 & 56 DU plus 16 front LEU pins with AmLi source & 2970 & $2970(1)$ & $39.9(6)$ & $1.9 \%$ \\
\hline 7 & 72 DU pins with no source & 45660 & $43.3(2)$ & $2.60(2)$ & $2.1 \%$ \\
\hline 8 & 40 DU plus 32 LEU pins with AmLi source & 3570 & $3096(1)$ & $55.9(7)$ & $1.5 \%$ \\
\hline 9 & 8 DU plus 64 LEU pins with AmLi source & 2700 & $3276(1)$ & $80.8(1)$ & $1.3 \%$ \\
\hline 10 & 72 LEU pins with AmLi source & 2700 & $3299(1)$ & $86.0(9)$ & $1.1 \%$ \\
\hline 11 & 72 LEU pins with no source & 1800 & $51.2(3)$ & $3.66(7)$ & $1.0 \%$ \\
\hline 12 & 72 LEU pins with AmLi source shifted to front & 1800 & $3206(1)$ & $90(1)$ & $1.1 \%$ \\
\hline 13 & 72 LEU pins with AmLi source shifted to back & 1800 & $3331(1)$ & $82(1)$ & $1.2 \%$ \\
\hline
\end{tabular}




\section{Efficiency and Dead Time Measurements}

The efficiency of the ABUNCL active configuration (3 detector slabs) was measured at LANL on May 14, 2013, by placing a ${ }^{252} \mathrm{Cf}$ source (A7-867) at the center of the detector volume and measuring the net singles rate (Run 3 in Table 2.2), giving 9.6(5)\%, compared to $9.4(5) \%$ measured at PNNL [Kouzes 2013].

The dead time of the system was measured using the two-source method [Henzlova 2010]. The two ${ }^{252} \mathrm{Cf}$ sources were used individually and together to get the singles and doubles rates (Runs 4, 6 and 7). In this method, three measurements of singles (S) and doubles (D) are made: 1) source 1 and a dummy source (to include the effect of scattering) placed next to each other are measured, 2) source 1 and source 2 together are measured, and 3) source 2 and the dummy source are measured. The dead time correction parameter, A, is then found iteratively as discussed below.

The dead time corrected doubles are given by [Henzlova 2010]:

$$
D_{\text {corr }}=D e^{\delta S}
$$

where

$$
\delta=A+\frac{A^{2}}{4} S
$$

in which $\mathrm{A}$ is the dead time correction parameter determined experimentally. By using the singles from source $1\left(\mathrm{~S}_{1}\right)$, singles from source $2\left(\mathrm{~S}_{2}\right)$, singles from the combination $\left(\mathrm{S}_{1+2}\right)$, doubles from source $1\left(\mathrm{D}_{1}\right)$, doubles from source $2\left(\mathrm{D}_{2}\right)$, and doubles form the combination $\left(\mathrm{D}_{1+2}\right)$, the parameter A can be varied until the following expression is true:

$$
D_{1} e^{\delta S_{1}}+D_{2} e^{\delta S_{2}}=D_{1+2} e^{\delta S_{1+2}}
$$

Based on the measured data listed in Table 2.2, the result for the dead time parameter $\delta$ was found to be $9.20 \times 10^{-7}$, corresponding to $920 \mathrm{~ns}$. 


\section{Long Term Drift}

Between May 14, 2013 and June 11, 2013, long measurements (2-6 days each) were made with two AmLi sources in place in the source cavity in the HDPE door (Runs 9-13 in Table 2.3). The total acquisition time was over 26 days. While the individual singles rates for the five runs had smaller statistical errors, the standard deviation between these measurements was $0.2 \%$, indicating some variation in efficiency over time.

The air temperature above the ABUNCL was monitored during the entire measurement period using an EL-USB-2-LCD temperature, humidity, and dew point data logger. The record of the temperature (sampled every five minutes, giving over 15,000 data points) in Rooms C-154 and $\mathrm{C}-157$ is seen in Figure 4.1. The average air temperature during this period was $24.6^{\circ} \mathrm{C}$, with a minimum of $22.0^{\circ} \mathrm{C}$ and a maximum of $32.5^{\circ} \mathrm{C}$. The spikes seen in the data are real transients that occurred around 7:30 AM each day, presumably due to air conditioning variations, having durations of tens of minutes. Note that the temperature had two dips of a couple degrees in the middle, and an increase of a couple degrees toward the end of the time period.

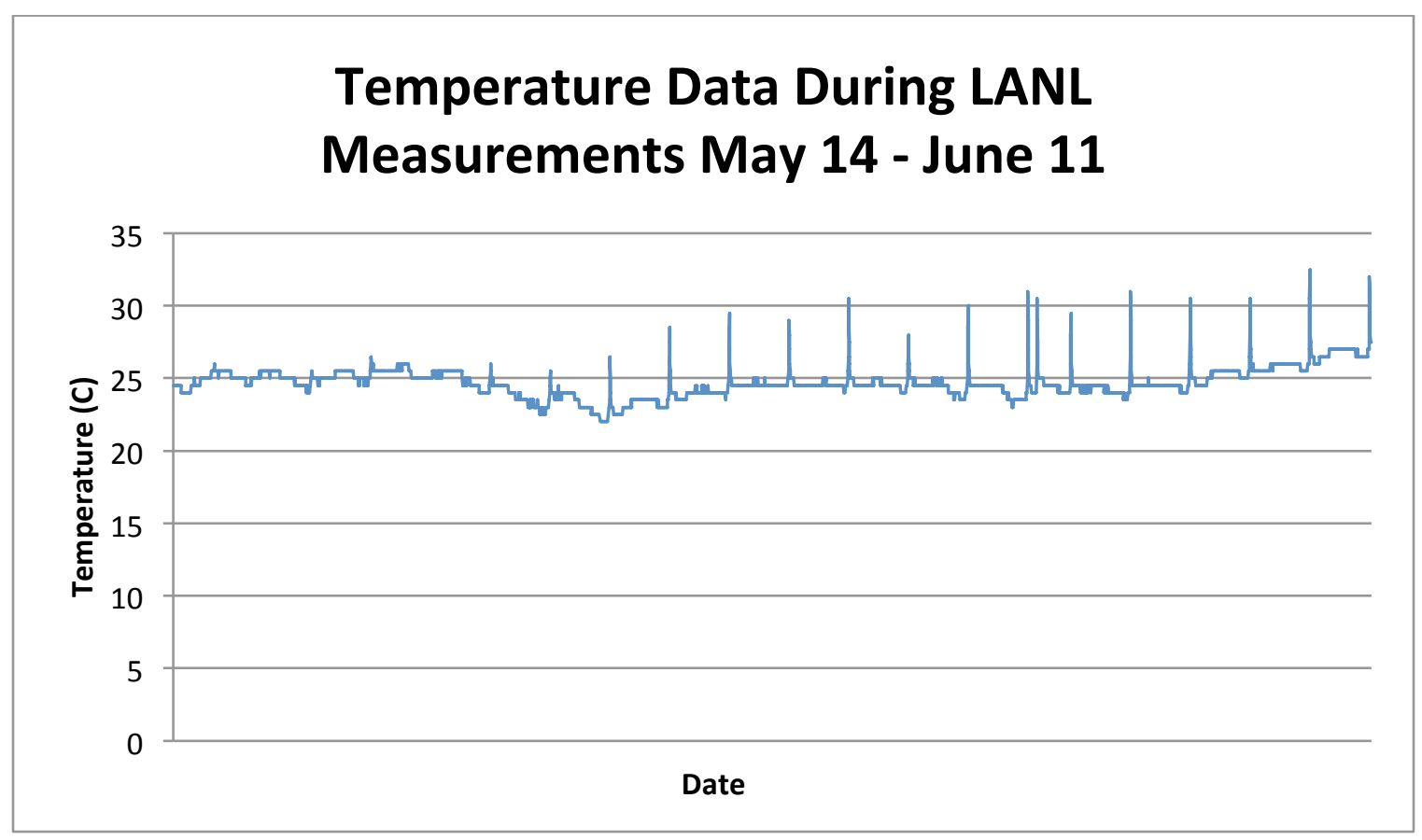

Figure 4.1. Temperature variation at LANL from May 14 to June 11, 2013 measured every 5 minutes.

The singles counts accumulated during the period from May 14 to June 11, 2013, are shown in Figure 4.2. Each value is counts per $600 \mathrm{~s}$. The vertical bar indicates a 1\% variation. There was almost a $1 \%$ swing in count rate over this one-month period from the highest to the lowest count value (well outside of statistical variation). There appears to be an anti-correlation in the counts 
with temperature variations observed, which could be explained as due to thermal expansion of the detector system, a shift in the electronics threshold affecting the efficiency, and temperature dependence in the neutron capture cross-section on boron (the thin-target thermal neutron crosssection decreases by $\left.\sim 0.17 \% /{ }^{\circ} \mathrm{C}\right)^{1}$ [Henzlova 2012]. The short temperature spikes do not seem to be reflected in the count rate data. The long duration temperature swings shown in Figure 4.1 (maximum of $5^{\circ} \mathrm{C}$ ) seem to anti-correlate with the change in singles rate shown in Figure 4.2. If the temperature deviations of a few degrees seen in Figure 4.1 are responsible for the change in efficiency, then it appears that the singles rate changes by about $0.25 \% /{ }^{\circ} \mathrm{C}$. It is unclear if the drop in efficiency over the entire time period is due to a slow downward drift in efficiency or is just due to environmental temperature changes. About two thirds of the change could be attributed to the cross-section temperature dependence.

This variation is perhaps an order of magnitude larger than that seen for ${ }^{3} \mathrm{He}$-based systems; thus, stabilizing the system against temperature changes may be needed. If the temperature in a facility is stable for many hours, this temperature dependence may not be a problem since detector efficiency can be determined from neutron singles measurements of a calibration source. A longer-term measurement in an environmental chamber should be performed to observe if the ABUNCL efficiency trend continues downward or correlates only with temperature.

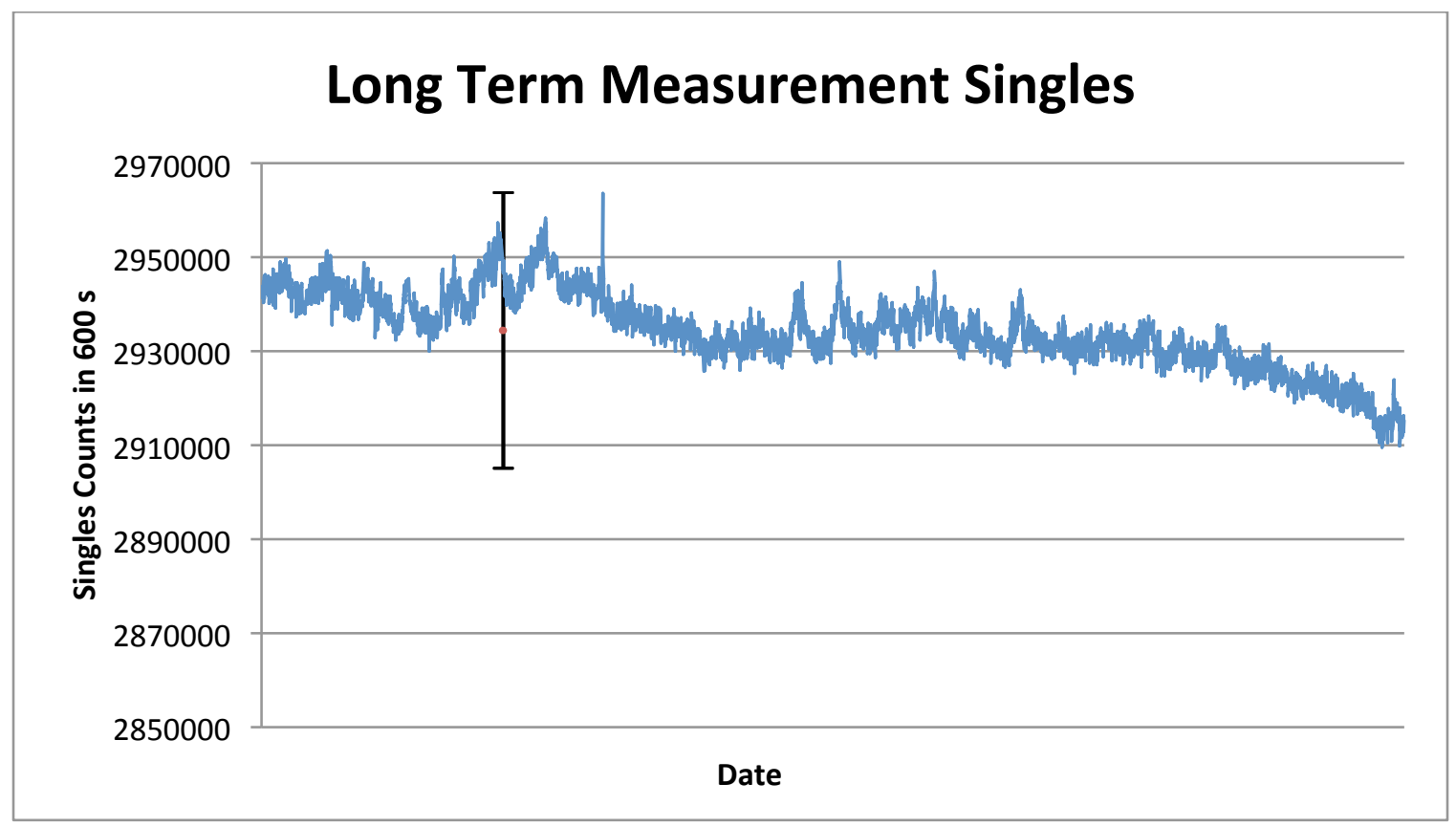

Figure 4.2. Singles counts at LANL from May 14 to June 11, 2013 measured every 10 minutes.

\footnotetext{
${ }^{1}$ Since the capture cross-section $(\sigma)$ varies as the inverse of the speed (v), and $\mathrm{v} \sim \sqrt{T}$, where $\mathrm{T}$ is temperature, then $\mathrm{d} \sigma / \sigma \sim-\mathrm{dT} / 2 \mathrm{~T}$. At room temperature $(\sim 300 \mathrm{~K}), \mathrm{d} \sigma / \sigma=0.17 \%$ per degree $\mathrm{C}$.
} 


\section{Fresh Fuel Measurements}

A series of measurements was made on June 11-12, 2013, on DU and LEU fuel arranged in a support rack, as seen in Figure 5.1 from above. The ABUNCL was arranged approximately on the center of the fuel assembly, both vertically and horizontally (the hole in the ABUNCL for fuel is rectangular rather than square). The fuel pins (138 cm long with $128 \mathrm{~cm}$ of fuel in each pin, $1 \mathrm{~cm}$ in diameter) were arranged in a $9 \times 9$ array (spaced at $1.4 \mathrm{~cm}$ ), which is consistent with a BWR assembly. There were 9 "guide" holes in the array, resulting in a total of 72 holes for fuel pins.

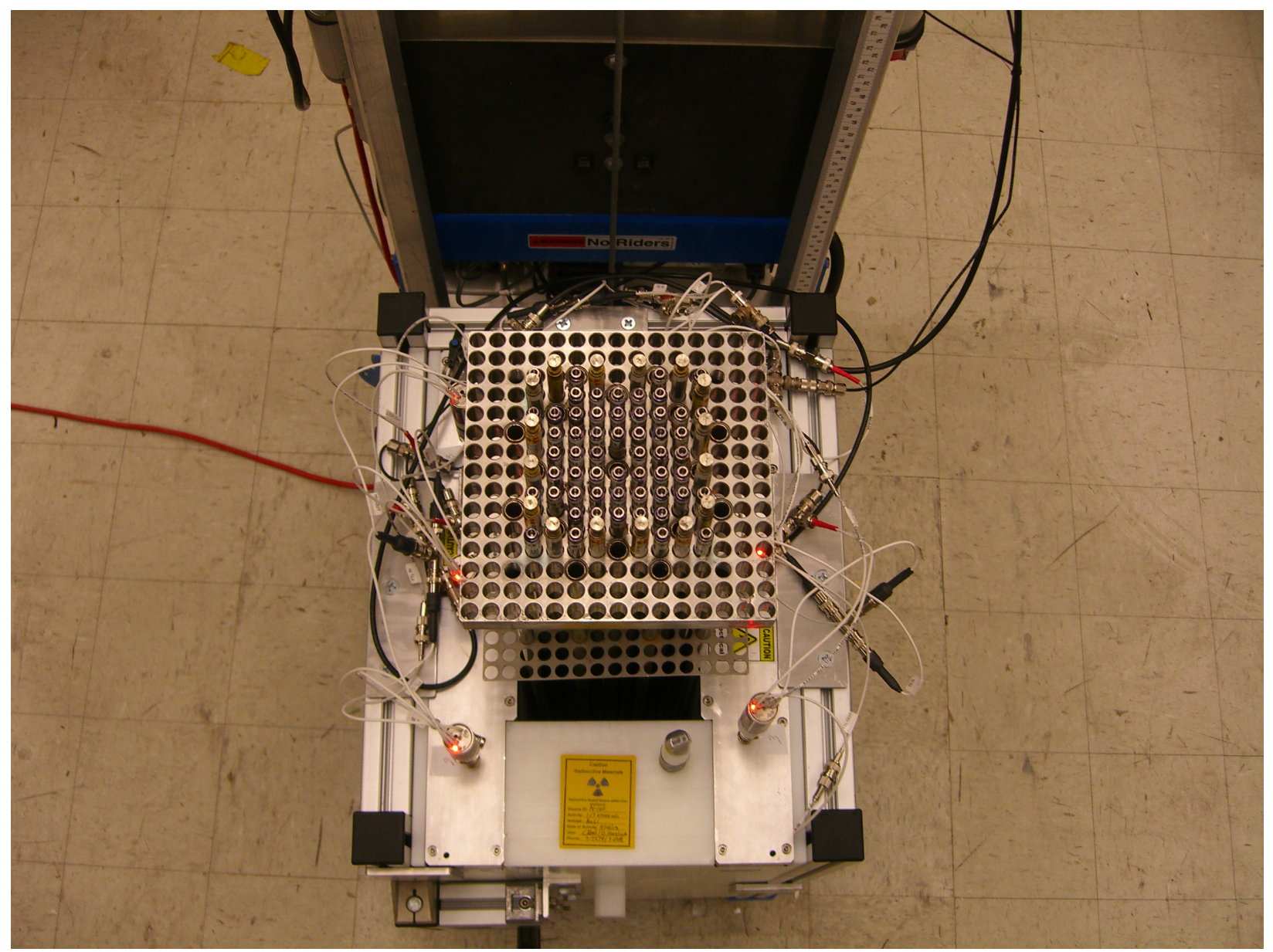

Figure 5.1. ABUNCL at LANL with fuel pins loaded (DU in the center, LEU on outside).

For all measurements, all 72 fuel pins (DU or LEU) were in place. A number of different configurations were measured, including all DU and all LEU fuel, and mixtures of each. Figure 5.2 shows a schematic of the various configurations measured. The outer line represents the $9 \times 9$ space. The black squares represent the guide holes, and the blue squares represent the LEU pins. All other white holes within the $9 \times 9$ array were filled with DU fuel pins. Configuration 0 was all DU pins. Measurements were made on 8 LEU pins (Configurations 1 and 2), 16 LEU pins 
(Configurations 3, 4, 5, and 6), 32 LEU pins (Configurations 7), 64 LEU pins (Configurations 8), and 72 LEU pins (not shown).

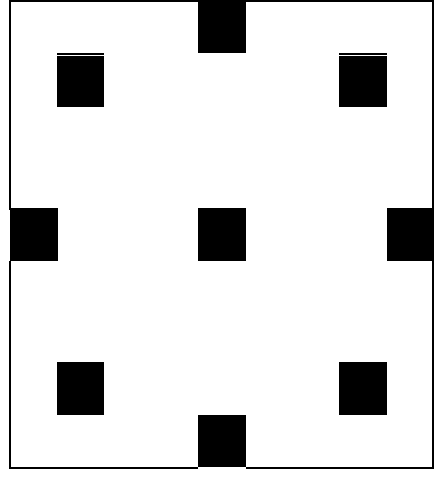

Config 0

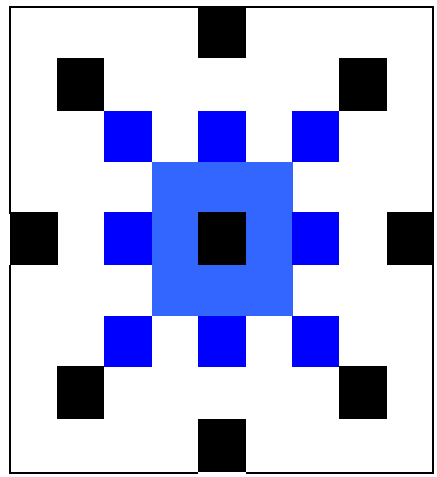

Config 3

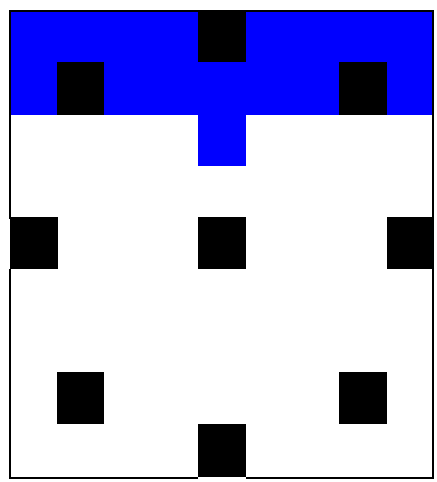

Config 6

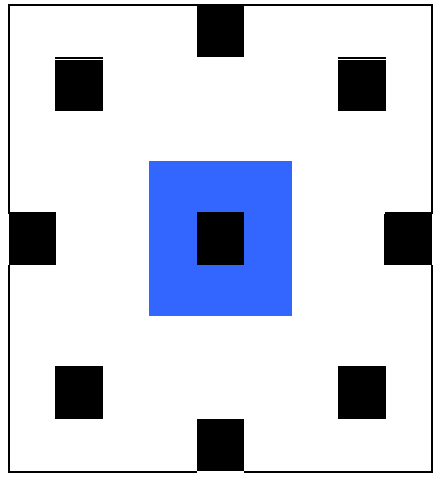

Config 1

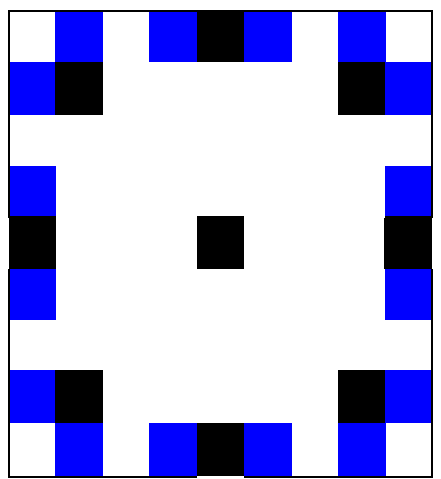

Config 4

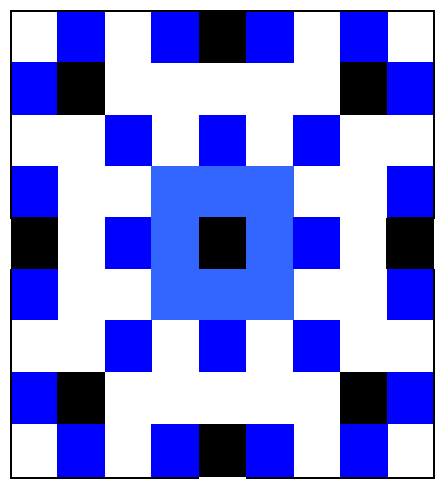

Config 7

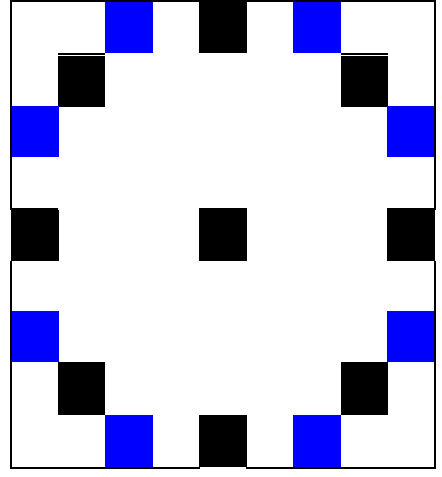

Config 2

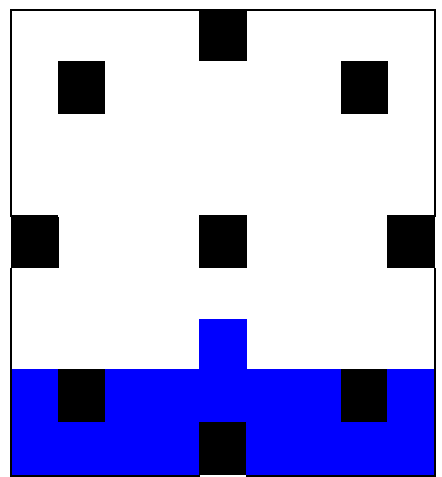

Config 5

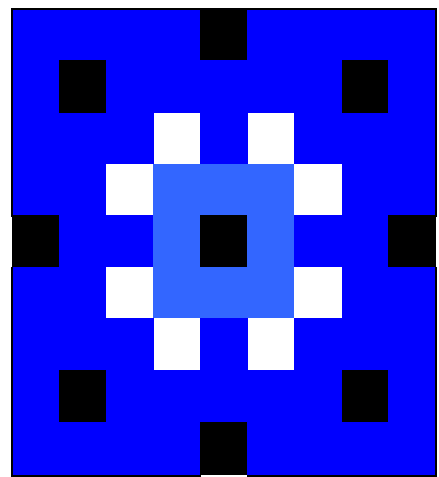

Config 8

Figure 5.2. Fuel configurations used during measurements, where blue represents LEU pins, black are guide tubes, white are DU pins. 
The data results from these measurements are summarized in Table 2.4. The doubles rates are plotted in Figure 5.3, where the red line is for no AmLi source and the green line is with the AmLi source loaded in the source holder location. Error bars are smaller than the markers. There is a general trend for a larger signal with more LEU pins, as expected. Based on such measurements, the mass of uranium in the assembly could be inferred if the system were calibrated with a reference fuel assembly to about $1 \%$ precision.

For the $16 \mathrm{LEU}$ pin data, placing the pins at the center or the rear of the assembly (away from the AmLi sources) reduces the signal compared to the other locations (around the outside, or at the front near the AmLi source). Moving the LEU pins from the front to the back of the pin assembly causes a $17 \%$ change in the doubles rate. This is a smaller effect than seen in the specific ${ }^{3} \mathrm{He}$-based UNCL geometry tested in 1981 [Menlove 1981], though that geometry was different than current UNCL designs.

For the $72 \mathrm{LEU}$ pin case, moving the entire assembly to the front (near the AmLi source) increases the signal, while moving it to the rear (away from the AmLi source) reduces the signal, with a $9 \%$ change in doubles rate.

As listed in Table 2.4, the measurement precision for the full LEU fuel load was $1.1 \%$ in 30 minutes. For a full DU load, it was about $2.2 \%$ in an hour. The desired precision for a LEU fuel assembly is a $1 \%$ measurement in 15 minutes. The fact that the ABUNCL takes twice as long to make a comparable measurement as a ${ }^{3} \mathrm{He}$-based UNCL may be acceptable to an inspector since longer times are usually needed to load and unload the fuel in the instrument.

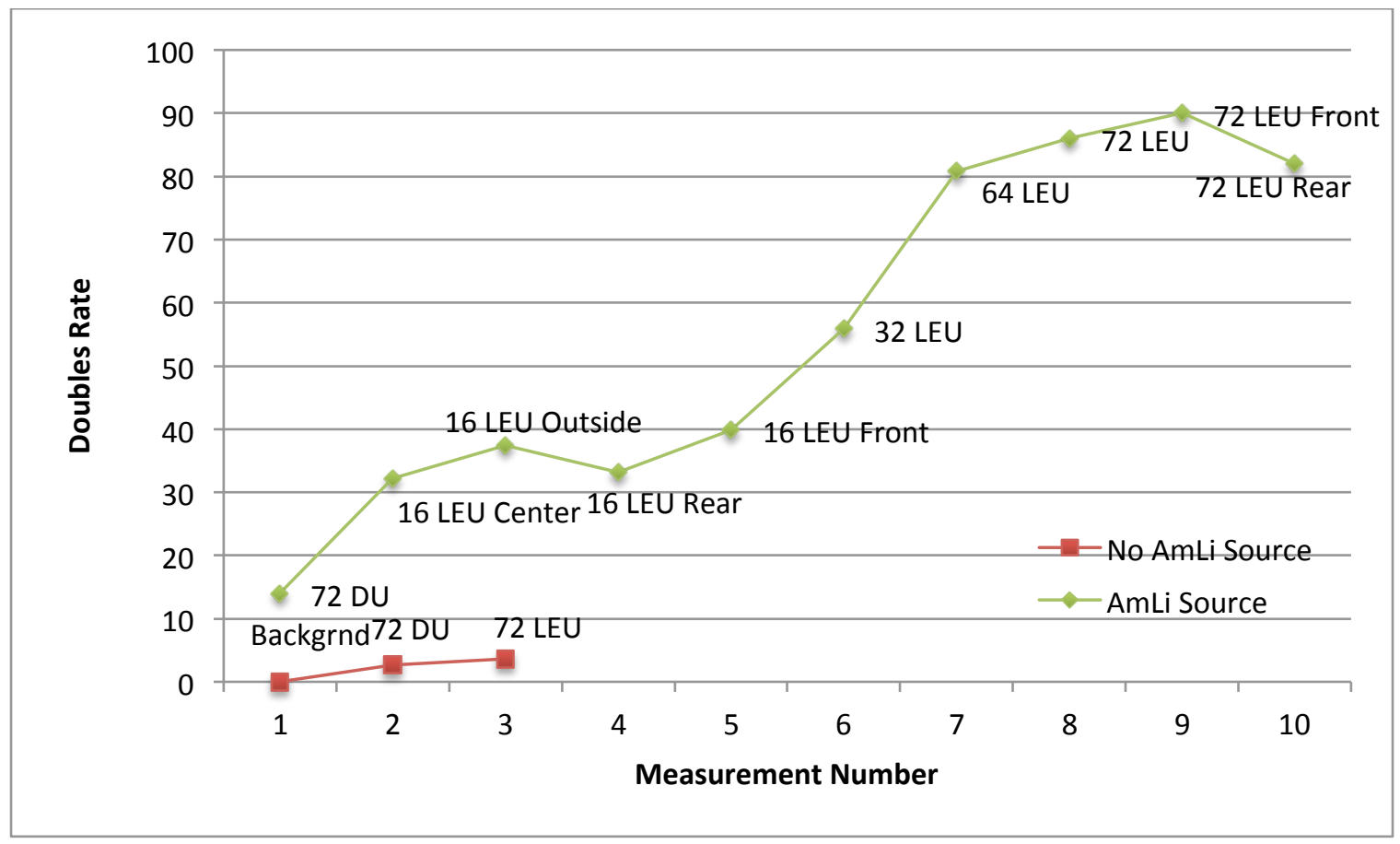

Figure 5.3. Doubles rates from fuel measurements. 


\section{Conclusions}

This report discussed the characterization of a full-scale boron-based ABUNCL coincidence counter developed by GE Reuter-Stokes for applications in safeguards under the project Coincidence Counting With Boron-Based Alternative Neutron Detection Technology.

Long dwell measurements were made on the system to determine stability. A decrease in efficiency was observed over a one-month period that correlated with a slow increase in average temperature. Measurements in an environmental chamber should be performed to determine if the changes were caused by temperature variation or if there is a slow decrease in efficiency due to other causes.

Results were provided from measurements on combinations of DU and LEU fuel from 72 DU pins up to 72 LEU pins in various combinations. The measurements at LANL indicate that a $1 \%$ doubles measurement can be made in about 30 minutes. This time period may be acceptable for safeguards measurements by inspectors, but that operational question needs to be answered by the IAEA.

Modeling with MCNPX [Pelowitz 2011] is planned for comparison to the measurements reported here. Each of the fuel configurations will be modeled to compare to these measurements. This will validate the predictive capability of the model for planning of future measurements. 


\section{Acknowledgements}

The United States Department of Energy Office of Nuclear Safeguards and Security (NA-241) supported this work. Pacific Northwest National Laboratory is operated for the United States Department of Energy under contract DE-AC05-76RLO 1830. Azaree Lintereur is a post Masters Research Assistant supported at Pacific Northwest National Laboratory by the Next Generation Safeguards Initiative, Office of Nuclear Safeguards and Security, National Nuclear Security Administration. We thank Dr. Daniela Henzlova for her assistance with measurements at LANL. 


\section{References}

Croft S, A Favalli, MT Swinhoe, CD Rael. 2011. "State Of The Art Monte Carlo Modeling Of Active Collar Measurements And Comparison With Experiment." Los Alamos National Laboratory. INMM Conference Record 2011.

Canberra. 2011. "Model JCC-71, 72 and 73 Neutron Coincidence Collars." Accessed at www.canberra.com.

Henzlova D, LG Evans, HO Menlove, MT Swinhoe, JB Marlow. 2010. "Draft Test Program to Compare Alternative Neutron Detectors for Potential ${ }^{3} \mathrm{He}$ Replacement for Nuclear Safeguards Applications." Technical Report LA-UR-11-00098, Los Alamos National Laboratory.

Henzlova D, LG Evans, HO Menlove, MT Swinhoe, V Henzl, C Rael, JB Marlow. 2012.

"Results of Evaluation and Comparison of Alternative Neutron Detectors for Potential ${ }^{3} \mathrm{He}$ Replacement for Nuclear Safeguards Applications.” Technical Report LA-UR-12-00837, Los Alamos National Laboratory.

Kouzes RT, JH Ely, LE Erikson, WJ Kernan, AT Lintereur, ER Siciliano, DL Stephens, DC Stromswold, RM Van Ginhoven, and ML Woodring. 2010. "Neutron detection alternatives for ${ }^{3}$ He homeland security." Nuclear Instruments and Methods in Physics Research A, 623(3):10351045.

Kouzes RT, JH Ely, AT Lintereur, and ER Siciliano. 2012. "Boron-10 ABUNCL Prototype Initial Testing." Technical Report PNNL-22147. Pacific Northwest National Laboratory, Richland, WA.

Kouzes RT, JH Ely, AT Lintereur, and ER Siciliano. 2013. "Boron-10 ABUNCL Prototype Models and Initial Active Testing." Technical Report PNNL-22424. Pacific Northwest National Laboratory, Richland, WA.

Krick M and W Geist. 2009. "INCC Software Users Manual." Technical Report LA-UR-106227, Los Alamos National Laboratory.

Pelowitz DB (ed.). 2011. “MCNPX User's Manual”, Version 2.7.0. Technical Report LA-CP-1100438 Los Alamos National Laboratory.

McKinny, K, T Anderson, N Johnson, E Weissman. 2012. Presentation at the IEEE Nuclear Science Symposium, Anaheim. CA, October 29, 2012.

Menlove HO. 1981. "Description and Performance Characteristics for the Neutron Coincidence Collar for the Verification of Reactor Fuel Assemblies.” Technical Report LA-8939-MS, Los Alamos National Laboratory.

Menlove HO, JE Stewart, SZ Qiao, TR Wenz, PD Verrecchia. 1990. "Neutron Collar Calibration and Evaluation for Assay of L WR Fuel Assemblies Containing Burnable Neutron Absorbers." Los Alamos National Laboratory Report LA-11965-MS.

Menlove HO, D Henzlova, LG Evans, MT Swinhoe, and JB Marlow. 2011. "3He Replacement for Nuclear Safeguards Applications - an Integrated Test Program to Compare Alternative Neutron Detectors." ESARDA Bulletin 46. 
Page 14 


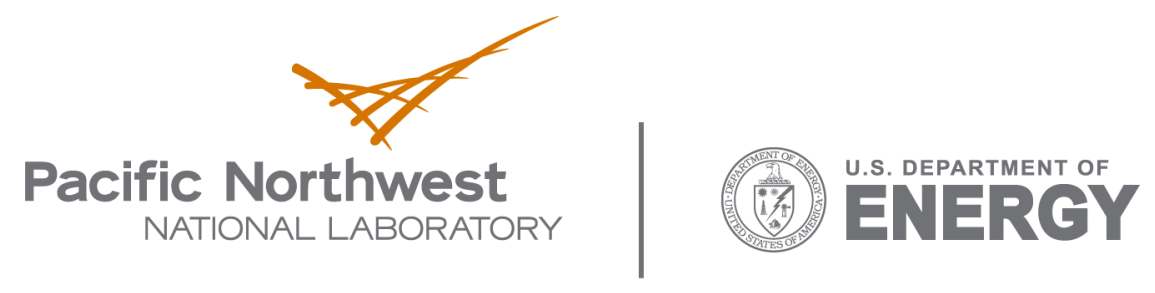

902 Battelle Boulevard

P.O. Box 999

Richland, WA 99352

1-888-375-PNNL (7665)

www.pnl.gov 